Special Issue: Russian Fracture Mechanics School

\title{
Tests in tension-torsion conditions with descending sections of strain curve construction
}

\author{
M.P. Tretiakov, V.E. Vildeman \\ Center of Experimental Mechanics, Perm National Research Polytechnic University, Komsomolskiy Pr. 29, 614990, Perm, \\ Russia \\ cem_tretyakov@mail.ru
}

\begin{abstract}
The paper is devoted to theoretical and experimental investigation of materials behavior on postcritical deformation stage (strain softening). Tests results, which confirm theoretical justification of specimen configuration impact on the possibility of creating descending sections of strain curve, are given. It is shown that, with sufficient stiffness of loading system, equilibrium postcritical deformation of materials is possible. It is confirmed in uniaxial tension tests with unloading on postcritical deformation stage. Test results on tension with torsion of thin-walled tubular specimens in strain softening conditions are adduced.
\end{abstract}

KEYWORDS. Experimental mechanics; Postcritical deformation; Proportional tension with torsion.

\section{INTRODUCTION}

$\mathrm{D}$ issipative processes of inelastic deformation, including the processes of structural failure and fracturing, reflect on the deformation curve as nonlinearity. At the final stage this leads to softening of materials and the appearance of a descending section on strain curve. Completeness of implementation of the load-carrying capacity of strength constructions is determined by the degree of postcritical deformation. When postcritical deformation stage is taken into account in adjusted computation, it allows a reserve of constructions load-carrying ability to be revealed. It makes possible to forecast the destruction moment more accurately [1, 2]. Questions of theoretical, experimental and numerical study of postcritical deformation mechanisms of materials attract attention of researches in connection with the questions of use of materials deformation reserves, the rise of load-carrying ability and survivability of materials, and the analysis of possibilities of failure processes management [1-9].

On the postcritical deformation stage the formation of macro-destruction conditions takes place. These conditions, unlike the traditional view that defines the use of force or deformation criteria are not definitely related to the stress-strain state at the point of deformed body. During the transition from the equilibrium stage of damage accumulation to nonequilibrium stage of destruction, interaction of the deformed body with the loading system plays the key role. As a result, based on loading conditions, each point on the descending section of stress-strain curve can correspond to the time of the loss of load-carrying ability as a result of transitioning from stable to non-equilibrium stage of the damage accumulation process. Thus, the rigid loading system may contribute to the "adaptation" of the object in the process of destruction due to local dissipation of elastic energy [1,2]. However the force or deformation criteria can be considered with a view to transition of material to postcritical strain stage (similarly the condition of transition to plastic state). It is necessary to experimentation verify of criteria, particularly by test results in plane stress state under combined tension-torsion loading [11- 13]. 
It is known that it is necessary to use high-stiffness test systems for obtaining equilibrium curves of materials postcritical deformation. However, even with high-stiffness test machine, in some cases obtaining descending sections of strain curve is not possible. It may be associated with specimen geometry. In work [10] a deformable body $\Omega$ is considered with boundary $\sum$ and contact type boundary conditions:

$$
\left.\left[\sigma_{i j}(\boldsymbol{r}) n_{j}+R_{i j}(\boldsymbol{r}) u_{j}(r)\right]\right|_{\Sigma_{s}}=S_{i}^{0}(\boldsymbol{r})
$$

where $R_{i j}$ are coefficients of loading system stiffness, $n_{j}(\boldsymbol{r})$ are direction cosines of normal vector to the surface of body $\Omega$ in the point with coordinate $r$. Defining relationship is written in the following form:

$$
d \sigma_{i j} \equiv C_{i j m n}^{\prime}(\varepsilon, \chi) d \varepsilon_{m n}
$$

where $\chi$ is indicator reflecting the nature of the process (active loading ( $\chi=1$ )or unloading). The condition of postcritical deformation stability in weakness zone $\Omega_{0}$ is written as follows:

$$
\int_{\Sigma} R_{i j} \delta u_{j} \delta u_{i} d \Sigma+\int_{\Omega-\Omega_{0}} C_{i j m n}^{\prime} \delta \varepsilon_{m n} \delta \varepsilon_{i j} d \Omega>\int_{\Omega_{0}} D_{i j m n} \delta \varepsilon_{m n} \delta \varepsilon_{i j} d \Omega
$$

where $D_{i j m n} \equiv-C_{i j m n}^{\prime}(\varepsilon, \chi=1)$ are components of softening modulus tensor. The sign of postcritical deformation is formulated in the following form:

$$
d \sigma_{i j} d \varepsilon_{i j}<0
$$

In a particular case of uniaxial deformation of a solid cylindrical specimen with length $l$ and cross section square $F$ and with weakness zone length $l^{\prime}$ and cross section square $F^{\prime}<F$, the main volume of the specimen is part of the loading system with respect to the weakness zone. It has been shown that the necessary condition of reaching postcritical deformation stage in the weakness zone is:

$$
Q_{0}>Q_{c}+Q_{M}
$$

where $Q_{M}=R_{M}^{-1}$ is compliance of test machine $\left(R_{M}\right.$ is stiffness of test machine), $Q_{c}=\left(l-l^{\prime}\right) /(E F)$ is compliance of bar (main volume), $Q_{0}=l^{\prime} /\left(D F^{\prime}\right)$ is compliance of the softening region $(D=-d \sigma / d \varepsilon$ is the current meaning of tangent softening modulus). Similarly for a thin-walled tubular specimen with length $l$ and moment of inertia $J_{p}$, with weakness region with length $l$ ' and moment of inertia $J_{p}^{\prime}\left(J_{p}^{\prime}<J_{p}\right)$, it can be seen that the condition necessary for postcritical stage realization in the weakness region under torsion can be written in the following form:

$$
L_{0}>L_{c}+L_{M}
$$

where $L_{M}=N_{M}^{-1}$ is the compliance of test machine on torsion ( $N_{M}$ is stiffness of test machine on torsion), $L_{c}=\left(l-l^{\prime}\right) /\left(G J_{p}\right)$ is the compliance of the bar on torsion (main volume), $L_{0}=l^{\prime} /\left(D_{G} J_{p}^{\prime}\right)$ is the compliance of the softening region on torsion $\left(D_{G}=-d \tau / d \gamma\right.$ is the current meaning of tangent softening modulus on torsion).

The aim of the work is experimental examination of the impact of loading system stiffness (particularly geometrical parameters of specimens) on the construction of strain curve with descending sections, and construction of strain curves with postcritical deformation stages in uniaxial tension and proportional tension-torsion tests.

\section{TESTS AND RESULTS}

\section{Test equipment}

ests were carried out on Instron 8850 biaxial servohydraulic test system (maximum load $100 \mathrm{kN}$, maximum torque $1000 \mathrm{Nm}$, cyclic tests with frequency up to $30 \mathrm{~Hz}$ ). Strain in the test part of specimen in uniaxial tension tests was registered by Instron 2620-601 extensometer, and in proportional tension-torsion tests it was registered by Epsilon 3550-010M biaxial extensometer. 


\section{Tests with various loading system stiffness}

Experimental investigation of the effect of stiffness of the loading system on the construction of strain curves with descending sections was performed in two test groups. In the first test group, solid cylindrical specimens with test part length of $10 \mathrm{~mm}$, diameter of $6 \mathrm{~mm}$ with additional deformation parts of different lengths (length of $30 \mathrm{~mm}, 60 \mathrm{~mm}$, diameter of $8 \mathrm{~mm}$ ) were used. In this case the additional test parts increased the compliance of the loading system with respect to the weakened central part. In the second test group specimens with different diameters $(5 \mathrm{~mm}, 10 \mathrm{~mm}, 13.5$ $\mathrm{mm}$ ) with the same ratio of test part length to diameter $\left(l_{0} / d=1\right)$ were used. In this case, the change of the specimen's diameter changes the specimen's stiffness and consequently changes the ratio of specimen stiffness to test machine stiffness.

In Fig. 1 the results of two test groups of steel 20 (GOST 1050-88) are shown. The influence of the loading system stiffness is reflected by the presence of different points on the descending section of strain curve, which correspond to the loss of stability moment of the deformation process. Stress is calculated as ratio of load to initial cross-section square of the specimen, the strain is $\varepsilon_{l n}=\ln (1+\varepsilon)$, where $\varepsilon$ is the ratio of extension by extensometer to initial gauge length.

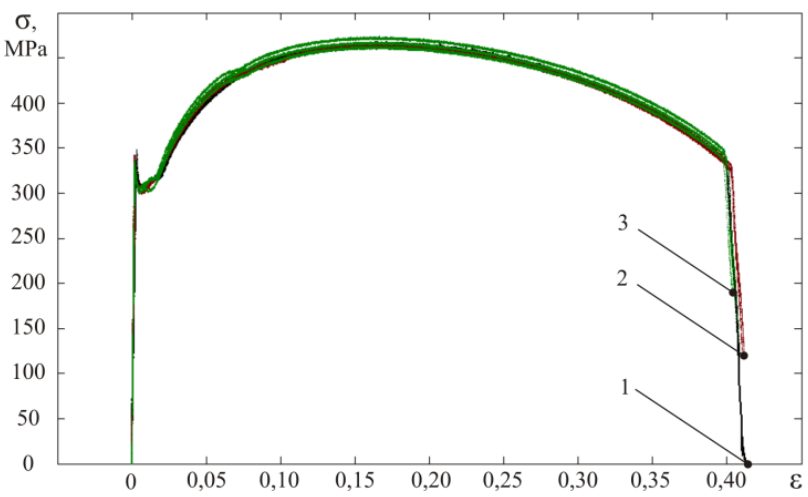

(a)

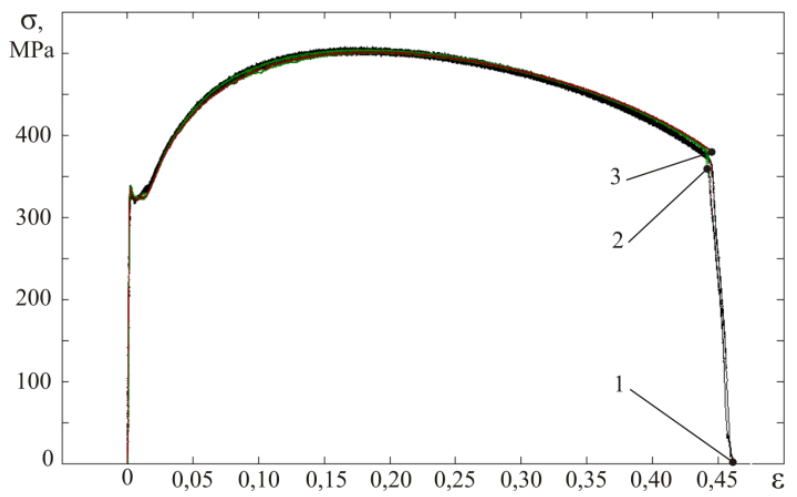

(b)

Figure 1: Strain curve of steel 20 and destruction moments: (a) is test results of specimens with additional elements (1 is specimen without additional elements, 2 and 3 are specimens with additional elements, with total lengths of $30 \mathrm{~mm}$ and $60 \mathrm{~mm}$ ), (b) is test results of specimens with different stiffness $(1,2$ and 3 are specimens with diameters $5.0 \mathrm{~mm}, 10.0 \mathrm{~mm}$ and $13.5 \mathrm{~mm}$.

The possibility of equilibrium material deformation on softening stage is also confirmed by unloadings and repeat loadings. In Fig. 2 the strain curve of steel 20 at uniaxial tension with unloading on different stages of elastoplastic and postcritical deformation ( $a$ ) and final section of softening with unloadings $(b)$ are shown. Strain rate at tension and unloading was $0.02 \mathrm{~min}^{-1}$.

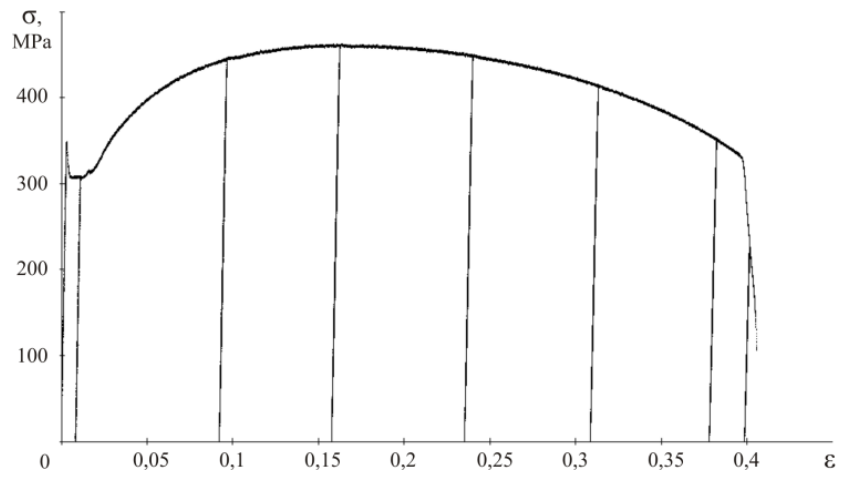

(a)

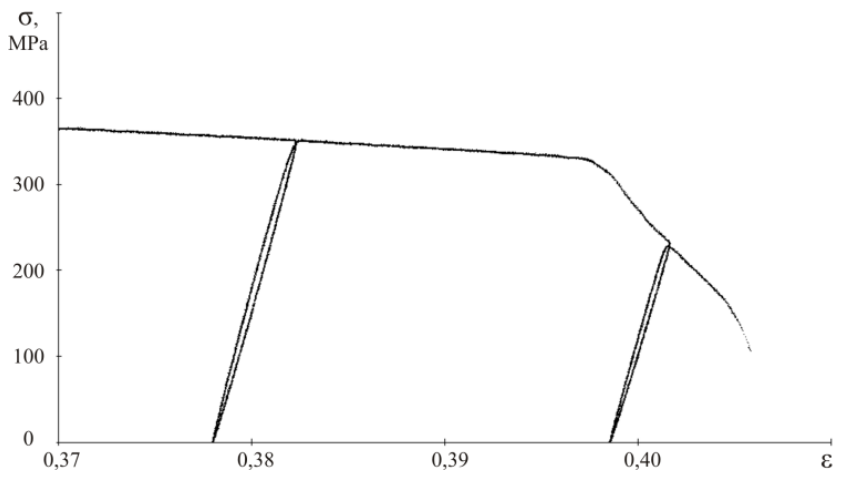

(b)

Figure 2: Strain curve of steel 20 at uniaxial tension: with unloading on different deformation stage (a), final section of strain curve (b).

Thus, to obtain equilibrium descending sections of the strain curve and complete curves (equilibrium drop of load to zero value), it is necessary to provide conditions of sufficient loading system stiffness with respect to test part of the specimen (high stiffness of the test machine, geometrical parameters of the specimen). With the above conditions, it is possible to 
obtain strain curves with sections of softening both under uniaxial tension and under tension combined with torsion. From the perspective of creation and improvement of postcritical deformation mechanics models the important question is the behavior of materials at a softening stage in combined tension-torsion conditions.

\section{Strain softening in tension-torsion tests}

Proportional tension-torsion tests were implemented on thin-walled tubular specimens of steel 40X (GOST 4543-71) and 15Х2ГМФ (TU 14-159-227-93 (RF Technical Requirements)) with reduced test part length. Shape and dimensions of specimens are shown in Fig. 3.

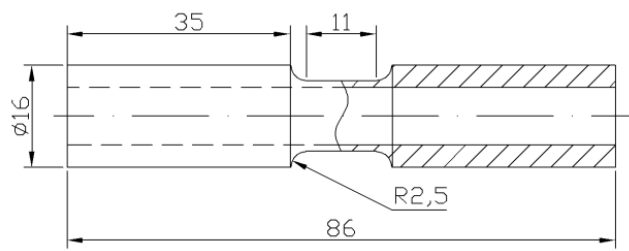

(a)

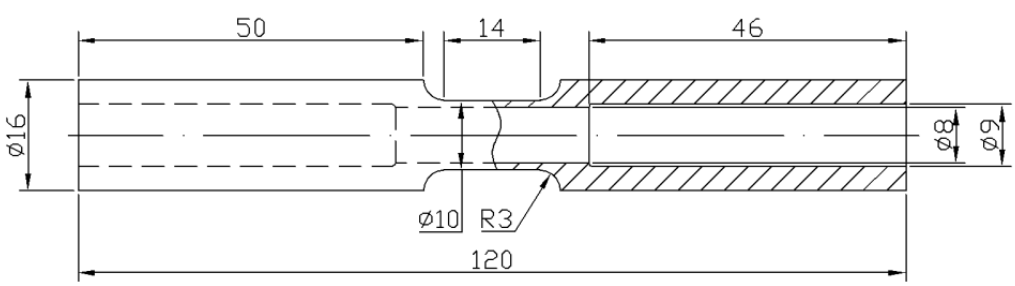

(b)

Figure 3: Shape and dimensions of thin-walled tubular specimens of steel 15X2ГMФ (a) and steel 40X (b).

Strain trajectories in deformation space correspond to straight lines. For steel $40 \mathrm{X}$ the ratio of axial strain to shear angle is 1.60 and 0.80 , for steel $15 \mathrm{X} 2 \Gamma \mathrm{M} \Phi$ it is 0.57 and 0.30 . The biaxial extensometer is intended for a small measurement range and it was used for correction of strain curves (by the linear section of the diagrams) which were obtained from the data of test system internal transducers. In Fig. 4 and Fig. 5 test results of steel 20 and 15Х2ГMФ at proportional tension with torsion are shown.

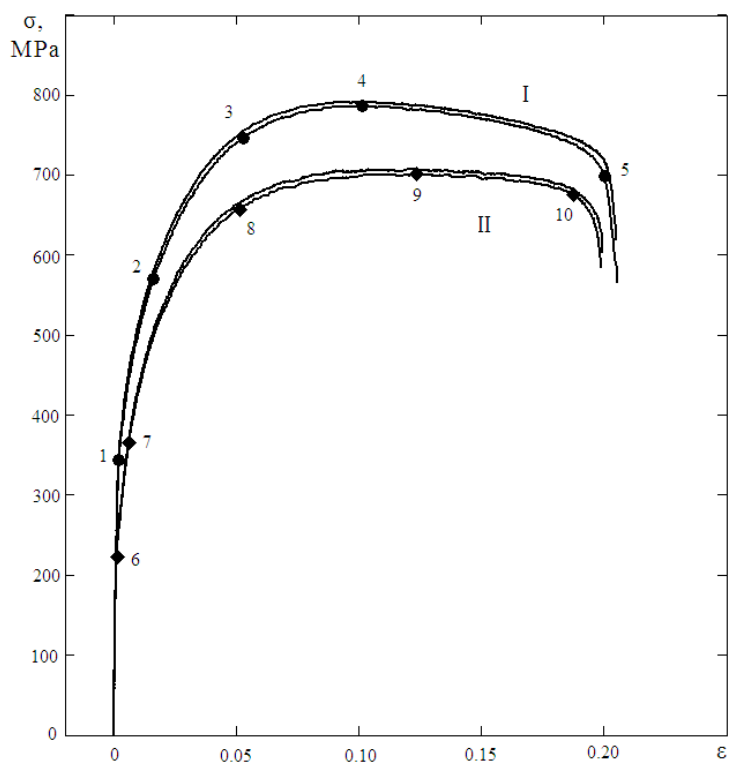

(a)

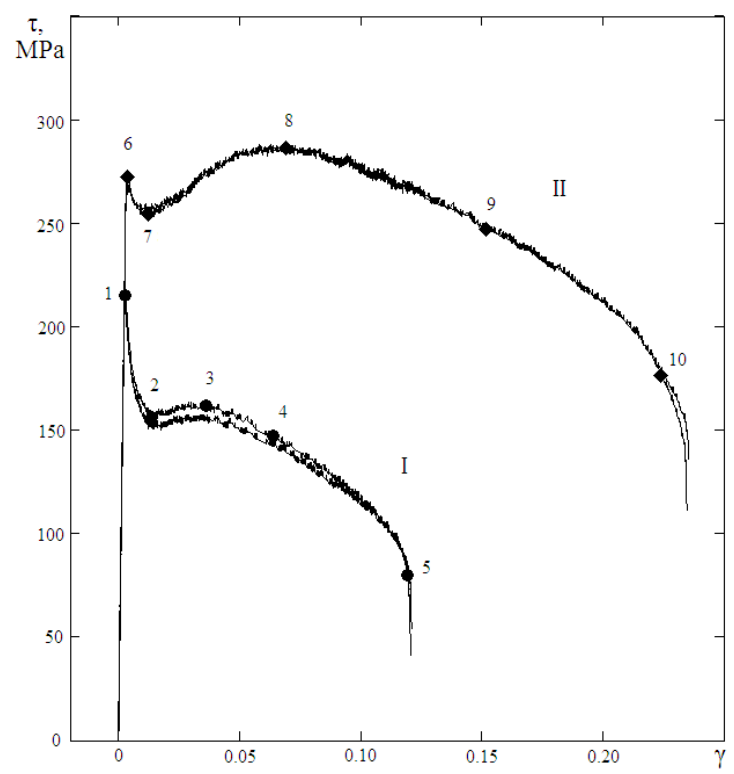

(b)

Figure 4: Test results of steel $40 \mathrm{X}$ at proportional tension-torsion with ratio $\varepsilon / \gamma=1.60$ (I) and $\varepsilon / \gamma=0.80$ (II) in coordinates "axial stress - axial strain" (a) and "shear stress - shear angle" (b). 
Stress is calculated as ratio of load to initial cross-section square of the specimen, the strain is $\varepsilon=\Delta l / l_{0}$, shear stress is $\tau=M /\left(2 \pi r^{2} h\right)$, shear angle is $\gamma=r \varphi / l_{0}$. In Fig. 4 the strain curves are presented which were constructed at tests of two specimens for each strain trajectories. For steel 15Х2ГМФ stress curves for the two specimens for each strain trajectories were obtained, in Fig. 5 results for one specimen are shown.

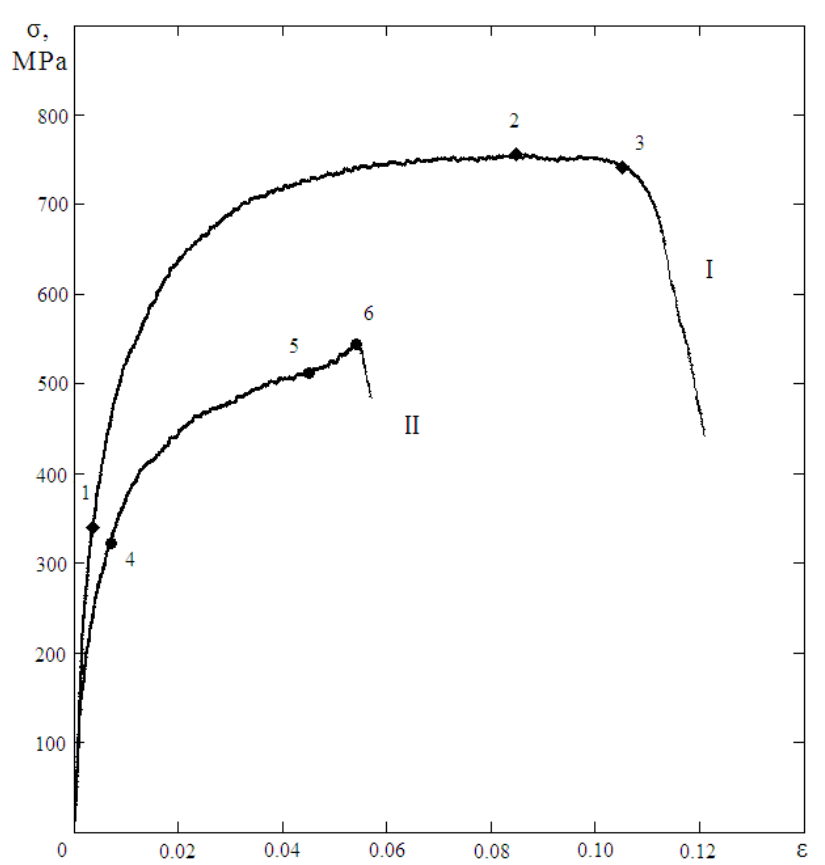

(a)

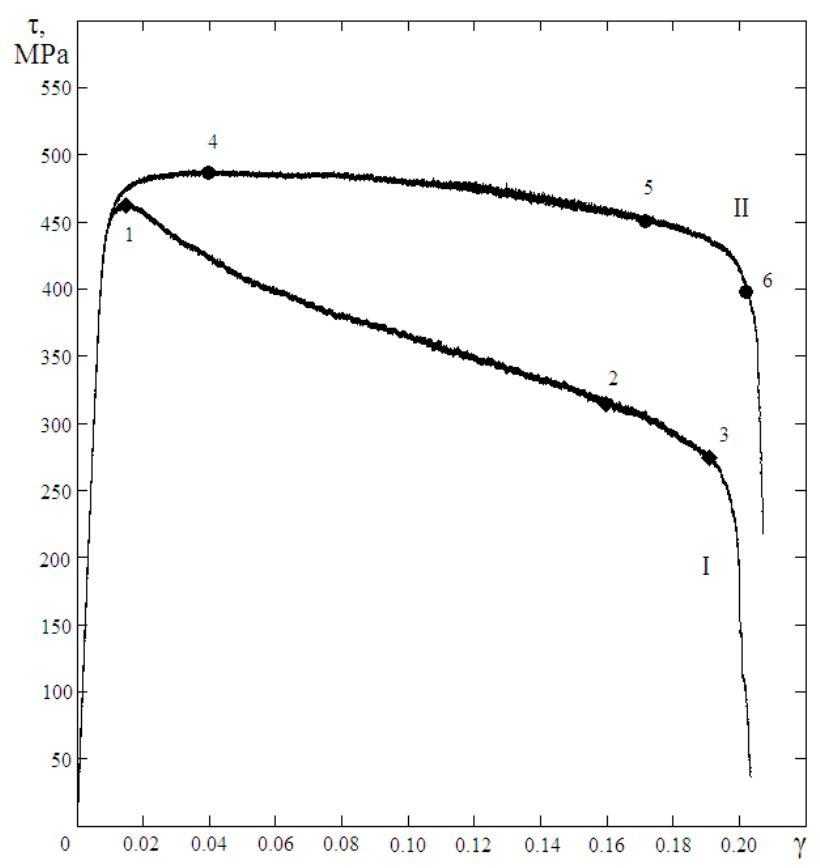

(b)

Figure 5: Test results of steel 15Х2ГMФ at proportional tension-torsion with ratio $\varepsilon / \gamma=0.57$ (I) and $\varepsilon / \gamma=0.30$ (II) in coordinates "axial stress - axial strain" (a) and "shear stress - shear angle" (b).

The important question is which deformation moment corresponds to the start of the softening stage, i.e. the reduction of loads at constant increase of strains. In Fig. 4 and Fig. 5 curves are marked with points and numbered for the convenience of comparison of strain curves in coordinates "axial stress - axial strain" and "shear stress - shear angle". In the analysis of experimental data diagram sections corresponding to the hardening of material at tension axis and shear axis can be highlighted. This corresponds to sections 2-3 and 7-8 in Fig. 4 and sections from limits of elasticity to points 1 and 4 in Fig. 5. There is also the strain range in which the softening of material at tension axis and shear axis occurs (the sections 4-5 and 9-10 in Fig. 4 and the sections from points 2 and 6 to specimen destruction in Fig. 5). It is necessary to draw special attention to areas of strain curves corresponding the hardening of material in coordinates "axial stress - axial strain" with synchronic softening in coordinates "shear stress - shear angle". The above is shown in sections of strain curves 3-4 and 8-9 in Fig. 4 and sections 1-2 and 4-6 in Fig. 5.

\section{CONCLUSIONS}

$\mathrm{I}$ $\mathrm{n}$ a result of this work, there is experimental confirmation of the influence of loading system stiffness with respect to test part of the specimen (geometrical parameters of the specimen) on realization of strain curve descending section at uniaxial tension. This is reflected in the presence of different points on the descending section which corresponds with the loss of deformation processes stability. The possibility of obtaining postcritical strain curves with sufficient stiffness of the loading system is confirmed by unloadings and repeated loadings at the softening stage under uniaxial tension.

The stress-strain curves of materials with softening sections at proportional tension with torsion of thin-walled tubular specimens are obtained at different trajectories of strain. It confirms the possibility of postcritical strain realization at different types of stress-strain state and allows us to obtain new data for creating models of softening medium mechanics. 


\section{REFERENCES}

[1] V.E. Vildeman, Yu.V. Sokolkin, A.A. Tashkinov, Mechanics of inelastic deformation and fracture of composite materials, (1997) 288.

[2] V.E. Vildeman, Int. J. for Computational Civil and Structural Engineering, 4(2) (2008) 43.

[3] V.E. Vildeman, Yu.V. Sokolkin, A.A. Tashkinov, Mechanics of Composite Materials, 28(3) (1992) 214.

[4] Yu.V. Sokolkin, V.E. Vildeman, Mechanics of Composite Materials, 29(2) (1993) 120.

[5] V.V. Struganov, Vestnik SSTU, Physics-mathematics science, 30 (2004) 5.

[6] V.V. Struganov, Physical Mesomechanics, 7(S1-1) (2004) 169.

[7] Yu.V. Sokolkin, V.E. Vildeman, A.V. Zaitsev, I.N. Rochev, Mechanics of Composite Materials, 34(2) (1998) 171.

[8] A.V. Ilinykh, M.V. Radionova, V.E. Vildeman, Composites: Mechanics, Computations, Applications, 2(2) (2011) 95.

[9] V.E. Wildemann, A.V. Ilyinykh, Physical Mesomechanics, 10(4) (2007) 23.

[10] V.E. Wildemann, J. Appl. Maths Mechs, 62(2) (1998) 281.

[11] S. Nohut, A. Usbeck, H. Özcoban, D. Krause, G.A. Schneider, Journal of the European Ceramic Society, 30 (2010) 3339.

[12] A.A. Lebedev, B.I. Kovalchuk, F.F. Gignyak, V.P. Lamashevskii, Mechanical properties of structural materials under complex stress state, (2003) 540.

[13] N.M. Zarroug, R. Padmanabhan, B.J. MacDonald, P. Young, M.S.J. Hashmi, J. of Materials Processing Technology, 143-144 (2003) 807.

\section{NOMENCLATURE}

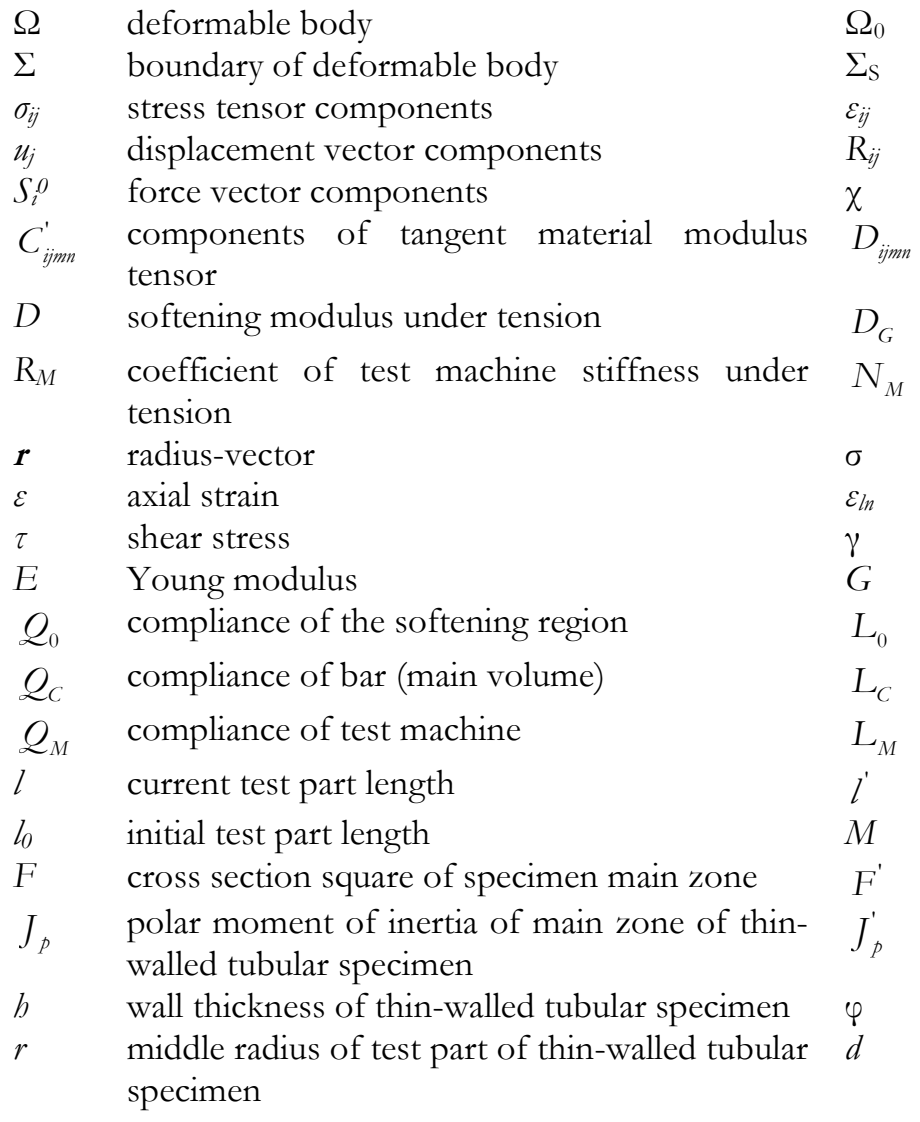

weak zone of deformable body

boundary part with force conditions

strain tensor components

loading system stiffness tensor components

indicator of the process nature

components of softening modulus tensor

softening modulus under shear

coefficient of test machine stiffness under torsion

axial stress

logarithmic axial strain

shear angle

shear modulus

compliance of the softening region on torsion

$L_{C} \quad$ compliance of bar (main volume) on torsion

$L_{M} \quad$ compliance of test machine on torsion

$l^{\prime} \quad$ length of specimen weak zone

$M$ torque

cross section square of specimen weak zone

polar moment of inertia of weak zone of thin-

walled tubular specimen

torsion angle

test part diameter of solid cylindrical specimen 